\title{
Antibody synthesis within the central nervous system: comparisons of CSF IgG indices and electrophoresis
}

\author{
EJ THOMPSON, * PG RICHES, $†$ J KOHN $\ddagger$
}

From the *Institute of Neurology, The National Hospital, Queen Square, London WC1, and the †Protein Reference Unit, Westminster Hospital, London SW1, and $\ddagger$ St Luke’s Hospital, Guildford, Surrey.

SUMMARY Various laboratories have reported differing success rates in their ability to detectc intrathecal synthesis of antibody when comparing the index of

$$
\text { CSF IgG: } \frac{\text { IgG } \frac{\text { CSF }}{\text { SER }}}{\text { Alb } \frac{C S F}{\text { SER }}}
$$

with electrophoretic analysis. We selected 44 patients in the borderline area of minimal and/o equivocal abnormality by IgG index. Electrophoretic analysis (on polyacrylamide gels for oligo $\stackrel{\overrightarrow{5}}{7}$ clonal gamma globulin pattern) of parallel specimens was performed at the same time. The number of samples giving a normal index but showing oligoclonal bands varied between $34 \%$ anफ $43 \%$ depending on the cut-off point. The views about normal barrier functions underlying such indices are discussed with particular reference to the pathophysiology of the blood-CSF barrier.

Detection of local synthesis of antibody within the central nervous system has been investigated by both qualitative and quantitative techniques. The earliest studies related the amount of CSF IgG to the total CSF proteins or albumin. ${ }^{1}$ The discriminant value of the CSF IgG to albumin ratio was further improved by reference to the serum concentrations of these two proteins. ${ }^{2}$ The value of the CSF IgG index is derived from the quotients of the serum and CSF concentrations of IgG and albumin according to the following relation:

\begin{tabular}{cc} 
IgG & $\frac{\text { CSF }}{\text { SER }}$ \\
\hline Alb & $\frac{\text { CSF }}{\text { SER }}$
\end{tabular}

There has been considerable discussion ${ }^{3-5}$ of the theoretical considerations which are involved in breakdown of the blood-CSF barrier. There is general agreement that the IgG index is valid in the normal range of CSF total proteins. However as the total protein increases, this assumption may not apply so the index has been reported either to change $^{367}$ in a curvilinear fashion or to remain linear. ${ }^{45}$ Some investigators have thus suggested that it may be preferable to relate the amounts of

Accepted for publication 28 October 1982
IgG to another larger protein, namely alpha- $2 \stackrel{\text { D }}{2}$ macroglobulin, in addition to the smaller protein albumin. ${ }^{35}$

\section{Material and methods}

Forty-four CSF samples were selected with IgCके index values in the borderline range of 0.4 to 1.2 (normal <0.85).

The albumin was estimated in CSF and serum b. electroimmunodiffusion using the Laurell rockes technique. ${ }^{8}$ The IgG was also estimated in CSF and serum by the rocket technique using agarose of higl electroendosmosis from Miles (Slough, UK) (Riches et al, 1983, in preparation). Antiserum against IgG was from Wellcome (London, UK) and antibod against albumin was from Dakopatts (Weybridge UK).

Polyacrylamide gel electrophoresis was per formed by a modification of the original Ornstein and Davis Technique' in which no upper gel was used.

Gels were assessed for the presence of two of more bands in the gamma region by visual inspeco tion as described. ${ }^{9}$

The gamma globulin region was divided into five sections as previously described. ${ }^{10}$ The gels were scanned by quantitative densitometry in a Joyc 
Loebl densitometer using Kodak Wratten filters (No 9 and 15) with a coefficient of variation of $7 \%$ (Johnson and Thompson, in press, 1983). The region of $\gamma_{1}$ through $\gamma_{5}$ was termed total gamma and mid $\gamma_{3}$ through $\gamma_{5}$ was termed slow gamma; the area under the curve from the densitometer tracing was determined by planimetry and this was then divided by the area under the curve for transferrin from the same densitometer tracing.

\section{Results}

Table 1 shows the number of patients divided according to the presence or absence of oligoclonal bands in the $\gamma$ region on polyacrylamide gel related

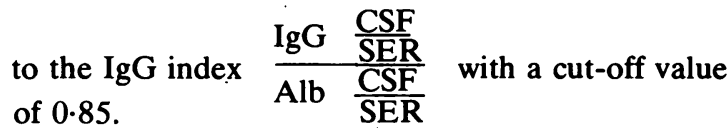

There were $8 / 24$ patients with both oligoclonal bands and an abnormal index and 16/24 patients with oligoclonal bands but a normal index. There were $17 / 20$ patients without oligoclonal bands and with a normal index, and $3 / 20$ patients without oligoclonal bands but with an abnormal index.

Table 1

\begin{tabular}{lll}
\hline & \multicolumn{3}{l}{ IgG Index } \\
\cline { 2 - 3 }$\geqslant 0.85$ & $\leqslant 0 \cdot 84$ \\
\hline $\begin{array}{l}\text { Oligoclonal bands present on PAGE } \\
(\mathrm{n}=24)\end{array}$ & 8 & 16 \\
$\begin{array}{l}\text { Oligoclonal bands absent by PAGE } \\
(\mathrm{n}=20)\end{array}$ & 3 & 17 \\
\hline
\end{tabular}

On the basis of oligoclonal bands being correct evidence of local synthesis of IgG within the central nervous system $19 / 44$ patients (43\%) would be incorrectly assigned by indices alone. If the data are recalculated on the basis of 0.82 or greater being abnormal, then $17 / 44$ patients $(38 \%)$ would still be incorrectly assigned by indices alone. This cut-off value gave the best discrimination of true-positives from false-positives.

Table 2 shows the same data when patients who were oligoclonal positive or negative were subdivided according to their individual index values derived from the albumin/IgG ratio in serum and CSF $^{112}$ when plotted according to the Figure. Equivocal results included off the graph due to a high total protein value as occurred in two such patients. This shows 10/24 patients with both oligoclonal bands and abnormal indices, 8/24 patients without an abnormal index but with oligoclonal bands and six equivocal indices with oligoclonal
Table 2

\begin{tabular}{llll}
\hline & \multicolumn{3}{l}{ Slope } \\
\cline { 2 - 4 } & Abnormal & Normal & Equivocal \\
\hline $\begin{array}{l}\text { Oligoclonal bands present on } \\
\text { PAGE }(\mathrm{n}=24)\end{array}$ & 10 & 8 & 6 \\
$\begin{array}{l}\text { Oligoclonal bands absent by } \\
\text { PAGE }(\mathrm{n}=20)\end{array}$ & 4 & 13 & 3 \\
\hline
\end{tabular}

bands present. There were $13 / 20$ patients with normal CSF results by both tests, $4 / 20$ patients had abnormal indices but without oligoclonal bands and three equivocal indices and no oligoclonal bands. Overall there were $21 / 44$ patients $(48 \%)$ who were not correctly classified with reference to the slope or were incorrectly classified on the basis of oligoclonal bands. Again if oligoclonal banding is correct, after exclusion of equivocal results then $12 / 35$ patients (34\%) were incorrectly classified by index (Figure).

Table 3 shows the same data when patients who were subdivided into those who had either oligoclonal bands or did not and were further subdivided according to whether the amount of total gamma proteins (estimated by densitometer area) as a quotient of transferrin (densitometry area) was $\geqslant 1 \cdot 98$. On the basis of oligoclonal bands providing the correct answer, this shows $11 / 24$ patients with raised total gamma protein values correctly classified and $13 / 24$ patients being incorrectly classified. It also shows $17 / 20$ patients with normal total gamma proteins correctly classified and $3 / 20$ false-positives.

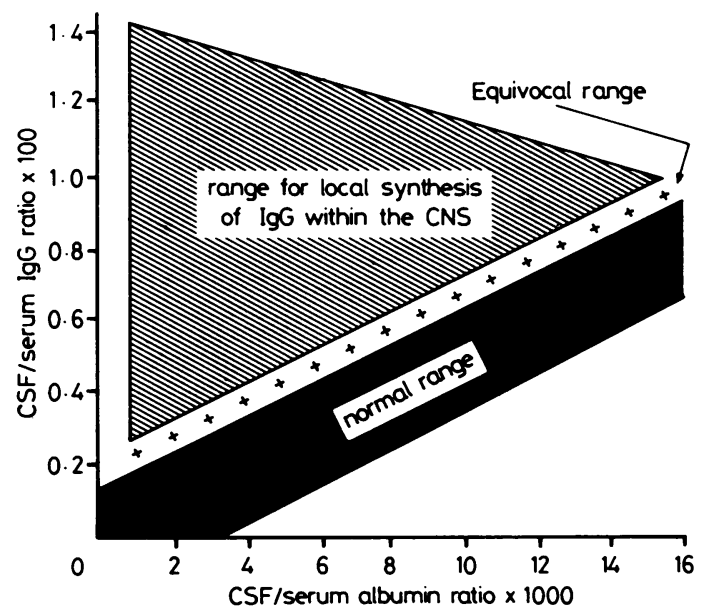

Fig. 1 Modification" of the Ganrot and Laurell" formulation of the ratio of CSF to serum albumin (on the $x$ axis) versus the ratio of CSF to serum IgG (on the $y$ axis). Values for albumin ratio greater than 16 were excluded. 
Table 3

\begin{tabular}{lll}
\hline & \multicolumn{2}{l}{ Total gamma/transferrin } \\
\cline { 2 - 3 } & $\geqslant 1.98$ & $\leqslant 1.97$ \\
\hline $\begin{array}{l}\text { Oligoclonal bands present on } \\
\text { PAGE } \mathrm{n}=24\end{array}$ & 11 & 13 \\
$\begin{array}{l}\text { Oligoclonal bands absent by } \\
\text { PAGE } \mathrm{n}=20\end{array}$ & 3 & 17 \\
\hline
\end{tabular}

Table 4

\begin{tabular}{llc}
\hline & \multicolumn{2}{l}{ Slow gammaltransferrin } \\
\cline { 2 - 3 }$\geqslant 0.89$ & $\leqslant 0.88$ \\
\hline $\begin{array}{l}\text { Oligoclonal bands present on } \\
\text { PAGE } \mathrm{n}=24\end{array}$ & 19 & 5 \\
$\begin{array}{l}\text { Oligoclonal bands absent by } \\
\text { PAGE } \mathrm{n}=20\end{array}$ & 3 & 17 \\
\hline
\end{tabular}

Overall there were $16 / 44$ patients $(36 \%)$ who were incorrectly assigned.

Table 4 shows the data when the same patients with or without oligoclonal bands were subdivided according to whether instead of total gamma the amount of slow (cathodic) gamma proteins (area) as a quotient of transferrin (area) was $\geqslant 0 \cdot 89$. This shows 19/24 patients with raised slow gamma proteins correctly classified as positive, and 5/24 misclassified false-negatives. It also shows $17 / 20$ patients with normal slow gamma as correct negatives and $3 / 20$ false-positives (the same three patients as in Tables 1,2 and 3). Overall $8 / 44$ patients $(18 \%)$ were incorrectly assigned.

\section{Discussion}

It is generally recognised that electrophoresis is the most discriminating test for the detection of local synthesis of IgG within the central nervous system. ${ }^{13}$ However, in many laboratories it is found to be more convenient to perform immunochemical $\stackrel{\vec{\sigma}}{\overrightarrow{0}}$ determination of $\mathrm{IgG}$ and albumin on serum and CSF. The quotient derived from such estimations $\stackrel{0}{f}$ can be expected to give a correct detection rate of 0 approximately $70-90 \% .{ }^{1415}$

It is clear from the present study that polyacrylamide gel electrophoresis is essential in those $\stackrel{\mathbb{D}}{\propto}$ samples where the quotient values are difficult to interpret because they fall within the borderline area.

Ratios of the amounts of gamma proteins to trans- $\overrightarrow{\vec{H}}$ ferrin derived from densitometric measurement are $\stackrel{\omega}{\circ}$ less reliable than visual inspection, however they 홍 may be more reliable than an index. The measure- $\omega$ ment of total gamma is less useful than that of the slow gamma for two reaons: (a) locally synthesised $\omega$ IgG is more cathodic than that derived from $\vec{N}$ plasma $^{16}$ and (b) the more anodic region may 음 include proteins other than $\mathrm{IgG}$, particularly $\operatorname{IgA}$. Comparison of our results with others is related 3 primarily to the question of patient selection. On either extreme, if one selects only normal subjects, $\stackrel{\circ}{\supset}$ or grossly abnormal subjects, high correlation $\vec{\varphi}$ coefficients are obtained between quantitative and $\underset{\omega}{\infty}$ qualitative analysis. However we chose on purpose those patients who were in the difficult grey zone by indices, in order to apply the most stringent tests to that category of patients which pose the most difficult diagnostic problem.

Table 5 shows the extent of disparity between various authors' figures for normal $(0.30$ to 0.67$)$ as well as abnormal $(0.50$ to 0.89$)$ indices. In general, the lower the index used as a cut-off value the greater the number of positive results, but simultaneously there is an increase in the number of false-융 positives. Bearing in mind the large scatter of values 0 in Table 5 , there are two criteria which must be 3 established in each laboratory: $(a)$ the normal index $\delta$ of IgG to albumin; (b) the standard deviation about this value.

Table 5

\begin{tabular}{|c|c|c|c|c|}
\hline Reference & $\begin{array}{l}\text { No of } \\
\text { patients }\end{array}$ & Mean $\pm S D$ & $C V$ & Mean $+2 S D$ \\
\hline $\begin{array}{l}\text { Delpech B, Lichtblau E }(1972)^{2} \\
\text { Ganrot K, Laurell CB }(1974)^{11} \\
\text { Felgenhauer }(1974)^{17} \\
\text { "Stokes radius" per Felgenhauer }(1974)^{17} \\
\text { Olsson JE, Pettersson B }(1976)^{14} \\
\text { Hansen NE, Karle H, Jensen A, Bock E (1977)'18 } \\
\text { Tibbling G, Link H, Ohman S (1977)'19 } \\
\text { Al-Kassab S, Dittmann L, Olesen H }(1979)^{20} \\
\text { Reiber H (1979) } \\
\text { Tourtellotte et al }(1980)^{22} \\
\text { Schuller E, Sagar HJ }(1981)^{23} \\
\text { This study }\end{array}$ & $\begin{array}{r}43 \\
54 \\
52 \\
52 \\
44 \\
15 \\
93 \\
36 \\
334 \\
70 \\
150 \\
44\end{array}$ & $\begin{array}{l}0 \cdot 52 \pm 0 \cdot 16 \\
0 \cdot 45 \\
0 \cdot 30 \\
0 \cdot 67 \\
0 \cdot 46 \pm 0 \cdot 10 \\
0 \cdot 47 \pm 0 \cdot 21 \\
0 \cdot 45 \pm 0 \cdot 07 \\
0 \cdot 56 \pm 0 \cdot 10 \\
0 \cdot 41 \pm 0 \cdot 11 \\
0 \cdot 43 \\
0 \cdot 41 \\
0 \cdot 63\end{array}$ & $\begin{array}{r}31 \% \\
? 16 \% \\
? 30 \% \\
? 15 \% \\
22 \% \\
45 \% \\
16 \% \\
18 \% \\
25 \% \\
? 15 \% \\
? 15 \% \\
? 15 \%\end{array}$ & $\begin{array}{l}0 \cdot 84 \\
0.59 \\
0 \cdot 50 \\
0 \cdot 88 \\
0 \cdot 66 \\
0 \cdot 89 \\
0 \cdot 59 \\
0.76 \\
0 \cdot 65 \\
0 \cdot 56 \\
0 \cdot 54 \\
0 \cdot 85\end{array}$ \\
\hline
\end{tabular}

$\mathrm{CV}=$ coefficient of variation. 
It is probable that interpretation of CSF indices could be improved by the use of common standard reagents and methods. This in turn would hopefully lead to a better definition of the role of the bloodCSF barrier in normal and pathological conditions. It would thereby help with the problem of determining local synthesis of IgG in the face of raised total CSF protein values.

This work was supported in part by a grant from the Medical Research Council.

\section{References}

' Kabat EA, Glusman M, Knaub V. Quantitative estimation of the albumin and gamma globulin in normal and pathologic cerebrospinal fluid by immunochemical methods. Am J Med 1948;4:653-62.

${ }^{2}$ Delpech B, Lichtblau E. Etude quantitative des immunoglobulines $\mathbf{G}$ et de l'albumine du liquide cephalo rachidien. Clin Chim Acta 1972;37:15-23.

${ }^{3}$ Reiber H. The discrimination between different blood-CSF barrier dysfunctions and inflammatory reactions of the CNS by a recent evaluation graph for the protein profile of cerebrospinal fluid. J Neurol 1980;224:89-99.

4 Felgenhauer K, Schliep G, Rapic N. Evaluation of the bloodCSF barrier by protein gradients and the humoral immune response within the central nervous system. J Neurol Sci 1976;30:113-28.

${ }^{5}$ Schliep G, Felgenhauer K. Serum-CSF protein gradients, the blood-CSF barrier and the local immune response. $J$ Neurol 1978;218:77-96.

- Eickhoff K, Heipertz R. Discrimination of elevated immunoglobulin concentrations in CSF due to inflammatory reaction of the central nervous system and blood-brain-barrier dysfunction. Acta Neurol Scand 1977;56:475-82.

7 Ganrot-Norlin K. Relative concentrations of albumin and IgG in cerebrospinal fluid in health and in acute meningitis. Scand $J$ Infect Dis 1978;10:57-60.

${ }^{8}$ Laurell C -B. Electroimmunoassay. Scand J Clin Lab Invest 1972;29: suppl 124:21-37.

9 Thompson EJ, Kaufmann P, Shortman RC, Rudge P, McDonald WI. Oligoclonal immunoglobulins and plasma cells in spinal fluid of patients with multiple sclerosis. Br Med J 1979;1:16-7.

${ }^{10}$ Thompson EJ. Oligoclonal gammaglobulin in relation to clinical classification in multiple sclerosis. In: Clifford Rose F., Ed. Clinical neuroimmunology, Oxford: Blackwell Scientific Publications, 1979.

"Ganrot K, Laurell C -B. Measurement of IgG and albumin content of cerebrospinal fluid, and its interpretation. Clin Chem 1974;20:571-3.

${ }^{12}$ Stitch SR. Specialized assay services for hospital laboratories. Leeds: University Printing Service, 1980.

${ }^{13}$ Poloni M, Rocchelli B, Scelsi R, Pinelli P. Intrathecal IgG synthesis in multiple sclerosis and other neurological diseases: a comparative evaluation by IgG-index and isoelectric focusing. J Neurol 1979;221:245-55.

${ }^{14}$ Olsson JE, Pettersson B. A comparison between agar gel electrophoresis and CSF serum quotients of $\mathrm{IgG}$ and albumin in neurological diseases. Acta Neurol Scand 1976;53:308-22.

${ }^{15}$ Christensen O, Clausen J, Fog T. Relationships between abnormal IgG index, oligoclonal bands, acute phase reactants and some clinical data in multiple sclerosis. J Neurol 1978;218:237-44.

${ }^{16}$ Laurenzi MA, Link H. Comparison between agarose gel electrophoresis and isoelectric focusing of CSF for demonstration of oligoclonal immunoglobulin bands in neurological disorders. Acta Neurol Scand 1978;58:148-56.

${ }^{17}$ Felgenhauer K. Protein size and cerebrospinal fluid composition. Klin Wochenschr 1974;52:1158-64.

18 Hansen NE, Karle H, Jensen A, Bock E. Lysozyme activity in cerebrospinal fluid. Acta Neurol Scand 1977;55:418-24.

19 Tibbling G, Link H, Ohman S. Principles of albumin and IgG analyses in neurological disorders. Scand J Clin Lab Invest 1977;37(5):385-90.

${ }^{20}$ Al-Kassab S, Dittmann L, Olesen H. IgG subclasses, barrier function for albumin and production of immunoglobulin $\mathrm{G}$ in the central nervous system. Acta Neurol Scand 1979;60:12939.

${ }^{21}$ Reiber H. Quantitative Bestimmung der Lokal im Zentralnervensystem synthetisierten Immunoglobulin G-Fraktion des Liqors. J Clin Chem Clin Biochem 1979;17:587-91.

${ }^{22}$ Tourtellotte WW, Potvin AR, Fleming JO, et al Multiple sclerosis: Measurement and validation of central nervous system IgG synthesis rate. Neurology 1980;30:240-4.

${ }^{23}$ Schuller E, Sagar HJ. Local synthesis of CSF immunoglobulins. A neuroimmunological classification. J Neurol Sci 1981;51:361-70.

Requests for reprints to: Dr EJ Thompson, Institute of Neurology, The National Hospital, Queen Square, London WC1, England 
References

' Stokes EJ, Ridgway GL. Clinical bacteriology. 5th ed. London: Edward Arnold, 1980.

${ }^{2}$ Zinnemann KS. Haemophilus infuenzae and its pathogenicity. Ergebnisse der Mikrobiologie, Immunitätsforschung and experimentellen Therapie 1960;33:307-68.

${ }^{3}$ Kilian M. A taxonomic study of the genus Haemophilus, with a proposal of a new species. J Gen Microbiol 1976;93:9-62.

Trimethoprim susceptibility to staphylococci

We have observed that inclusion of 1(4-nitrophenyl)-glycerol (PNPG) as an anti swarming agent in antibiotic susceptibility tests can give rise to anomalous results.

We performed disc tests in parallel to break point sensitivity tests in our studies. Isosensitest agar (Oxoid) with $5 \%$ added lysed blood and NAD was used in both methods, but PNPG was added at a final concentration of $50 \mathrm{mg} / 1$ (the concentration suggested by Mast Laboratories) to plates used in the break point method. The final concentration of trimethoprim used in the break point method was $0.5 \mathrm{mg} / \mathrm{l}$ and discs containing trimethoprim $1.25 \mu \mathrm{g}$ were used in the disc diffusion method.

Forty-five of 118 clinical isolates of Staphylococcus aureus and 11 of 34 coagulase-negative staphylococci were resistant by the break point method, but all were sensitive by the disc method. Subsequent isolates were tested for susceptibility to trimethoprim by the break point method using media with and without added PNPG. Thirty of 90 strains of Staph aureus and one of 21 coagulase-negative staphylococci were found to be resistant only in the presence of PNPG. In tests to determine the minimum inhibitory concentration (MIC) of trimethoprim, all resistant isolates were inhibited by $0.25 \mathrm{mg} / 1$ without PNPG, but the MIC was $1.0 \mathrm{mg} / \mathrm{l}$ in its presence.

We wish to draw attention to our findings, which we have only observed when testing the susceptibility of staphylococci to trimethoprim. Reduction of the concentration of PNPG to $15 \mathrm{mg} / \mathrm{l}$ inhibits the swarming of proteus in our hands, but does not produce anomalous results in trimethoprim susceptibility.

M OULD

C ROYCROFT

RH GEORGE

Department of Microbiology, Children's Hospital, Ladywood,

Birmingham B16 8ET

\section{Book reviews}

Immunofiuorescence Technology. Selected theoretical and clinical aspects. Ed G Wick, KN Traill and K Shauenstein. (Pp 442; \$60.) Elsevier Biomedical Press BV. 1982.

This valuable book draws together information on the theory and practice of immunofluorescence. The fifteen chapters, on selected topics, are without exception clearly written. In the first part of the book the authors discuss the theoretical basis of immunofluorescence and ways of standardising the methods, as well as describing the techniques and instruments for measuring it. In the second part they discuss immunostaining techniques and their applications to pathology, in particular to identification of autoimmune sera, renal disease, and immune complexes. Throughout the book the reader is led gently through the complexities and finishes each chapter with useful insights into the problems. Details of the authors' individual ways of carrying out the techniques include the practical tips that are all too often omitted. Some bias towards the authors' preferred methods is apparent, but the bibliography is extensive, up to 1980 , and references are given in full. The book is well illustrated and exceptionally clearly printed.

JULIA M POLAK

Anaerobic Infections. Public Health Laboratory Monograph Series. 3rd ed. AT Willis and KD Phillips. (Pp 53; paperback £2·75.) HMSO.

The Luton team now adds to its significant contributions to clinical anaerobic bacteriology by giving us a clear and straightforward guide that takes account of the considerable advances of the last decade, especially in relation to the non-sporing anaerobes. This new monograph is a fine example of realistic condensation based on much experience. There is obvious self discipline in restricting the text to useful simplified accounts. The practical methodology is within the compass of a busy clinical laboratory, and helpful Tables and identification schemes are easy to follow. Aerotolerant and microaerophilic species are included, with guidance on campylobacter isolation and identification. There is a very helpful general section on media and methods, and an informative note on gas-liquid chromatography.

This is essential reading for all clinical bacteriologists and it will be in constant demand at the bench.

\section{Some new titles}

The receipt of these books is acknowledged, and this listing must be regarded as sufficient return for the courtesy of the sender. Books that appear to be of particular interest will be reviewed as space permits.

Symposium on Vascular Malformations and Melanotic Lesions. Vol 22. Plastic Surgery Educational Foundation of the American Society of Plastic and Reconstructive Surgeons. Ed H Bruce Williams (Pp 421; £62.75.) Year Book Medical Publishers Ltd. 1983.

N-Nitroso Compounds: Occurrence and Biological Efiects. Proceedings of the VIIth International Symposium on N-Nitroso Compounds held in Tokyo 1981. Ed H Bartsch, M Castegnaro, IK O'Neill and M Okada. (Pp 755; Sw fr 110.) World Health Organisation. 1982.

Renal Insufficiency in Children. Ed Monika Bulla. (Pp 235; Soft cover DM 96.) Springer. 1982.

Stem Cells. Their Identification and Characterisation. Ed CS Potten. (Pp 404; £24.) Churchill Livingstone. 1983.

\section{Correction}

With reference to the article by Thompson et al in the March 1983 issue' Professor Kohn's present address is now: Department of Clinical Pathology, Royal Marsden Hospital, Downs Road, Sutton, Surrey.

\footnotetext{
Reference

' Thompson EJ, Riches PG, Kohn J. Antibody synthesis within the central nervous system: comparisons of CSF IgG indices and electrophoresis. J Clin Pathol 1983;36:312-5.
} 